\title{
Spatial modelling and mapping of female genital mutilation in Kenya
}

Thomas NO Achia ${ }^{1,2}$

\begin{abstract}
Background: Female genital mutilation/cutting (FGM/C) is still prevalent in several communities in Kenya and other areas in Africa, as well as being practiced by some migrants from African countries living in other parts of the world. This study aimed at detecting clustering of FGM/C in Kenya, and identifying those areas within the country where women still intend to continue the practice. A broader goal of the study was to identify geographical areas where the practice continues unabated and where broad intervention strategies need to be introduced.

Methods: The prevalence of FGM/C was investigated using the 2008 Kenya Demographic and Health Survey (KDHS) data. The $2008 \mathrm{KDHS}$ used a multistage stratified random sampling plan to select women of reproductive age (15-49 years) and asked questions concerning their FGM/C status and their support for the continuation of FGM/C. A spatial scan statistical analysis was carried out using SaTScan ${ }^{\mathrm{TM}}$ to test for statistically significant clustering of the practice of FGM/C in the country. The risk of FGM/C was also modelled and mapped using a hierarchical spatial model under the Integrated Nested Laplace approximation approach using the INLA library in R.
\end{abstract}

Results: The prevalence of FGM/C stood at $28.2 \%$ and an estimated $10.3 \%$ of the women interviewed indicated that they supported the continuation of FGM. On the basis of the Deviance Information Criterion (DIC), hierarchical spatial models with spatially structured random effects were found to best fit the data for both response variables considered. Age, region, rural-urban classification, education, marital status, religion, socioeconomic status and media exposure were found to be significantly associated with FGM/C. The current FGM/C status of a woman was also a significant predictor of support for the continuation of FGM/C. Spatial scan statistics confirm FGM clusters in the North-Eastern and South-Western regions of Kenya $(p<0.001)$.

Conclusion: This suggests that the fight against FGM/C in Kenya is not yet over. There are still deep cultural and religious beliefs to be addressed in a bid to eradicate the practice. Interventions by government and other stakeholders must address these challenges and target the identified clusters.

Keywords: Spatial hierarchical Bayesian analysis, Female genital mutilation, Integrated Nested Laplace Approximation, Disease mapping

\section{Background}

Female Genital Mutilation/Cutting (FGM/C) has been described as the partial or total removal of the female genitalia or other injury to the female genital organs for cultural or other non-therapeutic reasons [1-3]. The practice is prevalent across the world with an estimated 100-140 million girls and women forcibly circumcised $[2,4]$. A greater number of women have also been

\footnotetext{
Correspondence: thomas.achia@wits.ac.za

${ }^{1}$ School of Public Health, University of Witwatersrand, Johannesburg, South Africa

${ }^{2}$ School of Public Health, University of the Western Cape, Western Cape, South Africa
}

socialized to embrace FGM/C as an integral part of womanhood. Many girls and women bleed to death, or suffer disabilities that make it difficult for them to give birth normally, resulting in the death of the baby or health complications for those mothers and babies that survive.

The complications faced and challenges presented in giving appropriate care to circumcised women is widely reported in the literature. In the short term such complications include shock, haemorrhage, severe pain, infection, urinary retention and psychological sequalae [5-9]. Long term complications include dermoid cysts at the 
site of the amputated clitoris, urinary problems such as pain at micturition, dribbling urine incontinence and poor urinary flow, an increased risk of childbirth complications and new-born deaths $[3,4,10]$. Other long term complications include fibrosis, primary infertility, disorders of desire/libido, arousal, pain/discomfort, and inhibited orgasm [9,11-13].

It is against this background that the Committee on the Elimination of All Forms of Discrimination against Women issued its General Recommendation on Female Circumcision (General Recommendation No 14) that calls upon states to take appropriate and effective measures with a view to eradicating the practice and requests them to provide information about measures being taken to eliminate $\mathrm{FGM} / \mathrm{C}$ in their reports to the Committee [14,15].

Kenya is home to an estimated 38.3 million people from more than 30 ethnic groups. It is also estimated that $\mathrm{FGM} / \mathrm{C}$ is practiced in more than three quarters of the country, with prevalence of the practice varying widely from one ethnic group to another. Prevalence rates differ by provinces with rates of $26.5 \%, 33.8 \%$ and $32.1 \%$ recorded in Central, Nyanza and Rift Valley provinces respectively. Recent data suggest a decline from highs of $38 \%$ in 1998 , to $32 \%$ and $27 \%$ in 2003 and $2008-9$ respectively. There are also marked age variations in FGM/C with $15 \%$ of women aged $15-19$ years and $49 \%$ of those aged 45-49 years circumcised [16,17]. Currents statistics also show that rural women are more likely than urban women to have been circumcised.

No articles were found in the literature survey that assessed regional, or even localized clusters of FGM/C, or the intention to continue the practice of $\mathrm{FGM} / \mathrm{C}$ in Kenya. Only a limited number of studies globally have utilized spatial analytics in studying FGM/C [18-20]. The primary aim of this study was to map the geographical variations in the practice of FGM/C in Kenya, and the existing support for the continuation of the practice within the country. This study was also carried out with the aim of detecting clustering of the practice and to determine whether the distribution of the practice reflected significant clustering or chance variability in the practice. A broader goal of the study was to identify 'hotspots' to base future research on to better understand determinants of FGM/C practice.

\section{Methods}

\section{The data}

The data used in this study was from the 2008 Kenya Demographic and Health Survey (KDHS). This was a national survey conducted by the National Council for Population and Development (NCPD) in collaboration with the Central Bureau of Statistics (CBS) and Macro International. The survey was national in scope and selected respondents using a two-stage stratified random sampling design and relied on a sampling frame maintained by the CBS. A questionnaire based on a model developed by the MEASURE DHS programme, with slight adjustments to reflect relevant issues in Kenya, was used to collect the survey data. Fieldwork was conducted between April and September 2008 and achieved an overall response rate of $97 \%$ of households and $96 \%$ of women aged 15-49 who were eligible for an individual interview.

The 2008 KDHS covered 8,444 women aged 15-49, and 3578 men aged 15-54 from 400 enumeration areas throughout Kenya. The survey collected detailed demographic and women's health care information. The Geographical Positioning System (GPS) coordinates for Enumeration Areas (EAs) in both urban and rural areas were also collected.

\section{Ethical considerations}

This study was based on secondary data with all participant identifiers removed. Survey procedures and instruments were approved by the Scientific and Ethical Review Committee of the Kenya Medical Research Institute (KEMRI) and by the Ethics Committee of the Opinion Research Corporation, Macro International Incorporated (ORC Macro Inc.), Calverton, USA. Ethical permission for use of the data in the present study was obtained from ORC Macro Inc.

Details concerning the data collection protocols are available on the Measures Demographic and Health Surveys (DHS) website (http://dhsprogram.com/).

\section{The response variables}

The study considered responses to the questions "Have you undergone FGM/C?" and "Should FGM/C be continued?" as the two response variables of interest.

All the analysis in this paper was conducted for each of these variables separately.

\section{Covariates}

Based on a survey of literature [3,21-32] and limitations inherent in the dataset used, we assessed the nature of the response variables and the following covariates: woman's age (15-19, 20-24, 25-29, 30-34, 35-39, 4044, 45-49); region of residence (Nairobi, Central, Coast, Eastern, Nyanza, Rift Valley, Western, North Eastern); type of place of residence (urban, rural); woman's level of education (no formal, primary, secondary, higher); religion (Roman Catholic, Protestant/other Christian, Muslim, no religion, other); socioeconomic status (poorest, poorer, middle, richer, richest); marital status (never married, married/living together, separated); occupation (not working, management, other); media exposure (low, medium, 
high). The current FGM/C status of the woman was used as a predictor of support for the continuation of FGM/C.

A media exposure index was derived using a Principal Components (factor) Analysis (PCA) ) [33] and was based on responses to questions asked on the frequency of watching television, the frequency of listening to radio, and the frequency of reading newspapers. The respondents were then classified as having low, medium or high media exposure.

The lowest category of each ordinal covariate was used as the reference category in the Hierarchical modelling phase of the data analysis. Nairobi province, the seat of the capital city of Kenya, was used as the reference category for the covariate region of residence.

\section{Bivariate data analysis}

In order to ensure that estimates derived in this study are representative at the national level, survey weights that were provided as part of the KDHS data set were accounted for in the statistical analysis. Basic frequencies and cross tabulations, correcting for weighting and stratification of the random samples, were carried out using the Stata SVY (survey) commands [34] for each responsecovariate relationship. Design weighted F and Chi-square values were used to assess the nature of the association between the response variables and the covariates.

\section{Hierarchical spatial modelling}

To model the relationship between the response variables and the predictors of interest, a hierarchical spatial modelling approach was used [35-38]. Hierarchical models allow us to borrow strength from neighbouring regions and the entire geographical region in order to stabilize estimates based on small, local sample sizes within sectors. Methodological details are described in detail elsewhere and are briefly outlined in the Appendix.

In this study, Model 1 shall denote the (Bayesian) ordinary logistic regression model, Model 2 the generalized linear mixed model with spatially unstructured random effects, Model 3 the generalized linear mixed model with spatially structured random effects, and finally, Model 4 the generalized linear mixed model with both the spatially structured and unstructured random effects. Each of these models was fitted to the dataset. However, we present unadjusted odds ratios for each of the covariates, adjusted results for the full model, with all covariates included and the best fitting model identified.

Bayesian inference was carried out using the $R$ library INLA [39] which implements the Integrated Nested Laplace approximation approach for latent Gaussian models [40,41].

Model comparison and selection was carried out on the basis of the deviance information criterion $(D I C)$, which is a measure of model complexity and fit. The DIC was used to compare complex hierarchical models [42]. Smaller values of $D I C$ indicate a better trade-off between complexity and fit of the model.

\section{Spatial cluster detection}

To identify significant FGM clusters we merged relevant household data, while adjusting for sampling weights, to obtain aggregated county level indicators of the proportion of women undergoing circumcision, and the proportion intending to have their eldest daughter circumcised. Spatial scan statistical analysis was carried out using $\operatorname{SaTScan}^{\mathrm{\tau M}}$ to test for statistically significant clustering of the practice of FGM in the country [43]. This program tests for spatial clustering using area (case and population at-risk) data, and outputs the location, approximate size and significance of identified clusters.

A data file containing raw FGM case and controls for the centroid (longitude and latitude coordinate) of each of the counties was obtained using GeoDa [44]. This data file was imported into SaTScan assuming a Bernoulli probability disease model (case, control and at-risk population data).

The presence of high-risk clusters was assessed for each of the categories of FGM practice. The $p$-values for maximum likelihood ratios were based on 9,999 Monte Carlo randomizations. An alpha level of 0.05 was used to assess statistical significance. Likelihood-ratio based test statistics and reported $p$-values account for multiple testing.

\section{Results}

\section{Summary statistics}

Table 1 presents the results of design weighted bivariate cross-tabulation of FGM/C with various covariates entertained. The national FGM/C prevalence rate stood at 28.2\% (95\% CI: 24.4-32.3\%). We found significant bivariate associations between FGM/C and all the covariates considered ( $\mathrm{p}<0.001$ ). The prevalence rate of FGM/C varied linearly from a high of 50.3\% (95\% CI: 43.3-57.3\%) among women aged $45-49$ years to $15.7 \%$ (95\% CI: $11.8-20.6 \%$ ) among women aged 15-19 years. We also found significant regional variation in FGM/C. The North Eastern province that borders Somalia and Ethiopia had an FGM/C prevalence rate of $97.6 \%$ (95\% CI: 91.6-99.4\%), more than triple the national prevalence rate. Other regions with high FGM/C prevalence rates were Nyanza 36.4\% (95\% CI: 23.0-52.2\%), Eastern 36.4\% (95\% CI: 28.0-45.6\%) and Rift Valley with $32.9 \%$ (95\% CI: 25.7-41.0\%). The results suggested a linear decline in FGM/C prevalence with education, socioeconomic status and media exposure. We also found a variation in FGM/C prevalence by religious affiliation. The prevalence of FGM/C among Muslims, women professing no religious affiliation and Roman Catholic 
Table 1 Distribution of female genital mutilation by selected covariates

\begin{tabular}{|c|c|c|c|c|}
\hline & Women circumcised & & FGM/C should continue & \\
\hline & $\mathrm{N}(\%)$ & & $N(\%)$ & \\
\hline Circumcised & & & & \\
\hline No & & & $5175(2.4)$ & \\
\hline Yes & & & 2434(30) & \\
\hline Age & & $p<0.001$ & & $p=0.908$ \\
\hline $15-19$ & 1633(15.7) & & 1543(9.9) & \\
\hline $20-24$ & $1667(21.9)$ & & 1586(10.7) & \\
\hline $25-29$ & 1368(26.1) & & $1300(10.7)$ & \\
\hline $30-34$ & 1129(31) & & $1071(9)$ & \\
\hline $35-39$ & $890(36.3)$ & & $842(10.7)$ & \\
\hline $40-44$ & $704(40.8)$ & & $659(10.4)$ & \\
\hline $45-49$ & $647(50.3)$ & & 608(10.9) & \\
\hline Region & & $p<0.001$ & & $p<0.001$ \\
\hline Nairobi & $925(14.1)$ & & $884(6)$ & \\
\hline Central & $962(26.8)$ & & $947(5.3)$ & \\
\hline Coast & 978(11.8) & & $895(5)$ & \\
\hline Eastern & 1114(36.4) & & 1094(9.3) & \\
\hline Nyanza & 1226(36.4) & & 1059(20.1) & \\
\hline Rift Valley & $1241(32.9)$ & & 1188(6.8) & \\
\hline Western & $985(0.8)$ & & $953(1.7)$ & \\
\hline North Eastern & 607(97.6) & & $589(92.5)$ & \\
\hline Type of place of residence & & $p<0.001$ & & $p<0.001$ \\
\hline Urban & 2529(4.4) & & $1153(22.1)$ & \\
\hline Rural & $5509(23.8)$ & & $3135(77.8)$ & \\
\hline Education & & $p<0.001$ & & $p<0.001$ \\
\hline No formal & $1120(61.3)$ & & 1053(41.6) & \\
\hline Primary & $4172(28.9)$ & & 3905(8.2) & \\
\hline Secondary & $2043(21.4)$ & & 1969(7.8) & \\
\hline Higher & $703(12)$ & & $682(2.2)$ & \\
\hline Marital status & & $p<0.001$ & & $p=0.002$ \\
\hline Never married & 2405(15.3) & & $2304(7.5)$ & \\
\hline Married, living together & $4817(34.4)$ & & $4546(11.7)$ & \\
\hline Separated & $816(31.1)$ & & 759(10.6) & \\
\hline Religion & & $p<0.001$ & & $p<0.001$ \\
\hline Roman Catholic & 1624(30.4) & & 1549(8.7) & \\
\hline Protestant/other Christian & $4932(24.2)$ & & $4678(6.9)$ & \\
\hline Muslim & $1292(54.8)$ & & 1207(43.3) & \\
\hline No religion & 138(47.3) & & 128(30.2) & \\
\hline Other & $44(6.9)$ & & $39(5.1)$ & \\
\hline Socioeconomic status & & $p<0.001$ & & $p<0.001$ \\
\hline Poorest & 1529(44.6) & & $1445(20.8)$ & \\
\hline Poorer & $1215(32.2)$ & & $1140(10.3)$ & \\
\hline Middle & $1407(30.2)$ & & 1334(10) & \\
\hline
\end{tabular}


Table 1 Distribution of female genital mutilation by selected covariates (Continued)

\begin{tabular}{|c|c|c|c|c|}
\hline Richer & $1560(26.7)$ & & $1481(7.1)$ & \\
\hline Richest & $2327(15.7)$ & & $2209(7)$ & \\
\hline Media exposure & & $p<0.001$ & & $p<0.001$ \\
\hline Low & 2299(44.3) & & 2161(19.7) & \\
\hline Mid & $2982(26.5)$ & & 2802(8.6) & \\
\hline High & 2743(18) & & 2632(5.3) & \\
\hline Occupation & & $p<0.001$ & & $p=0.02$ \\
\hline Not working & $3535(24.4)$ & & $3327(11.9)$ & \\
\hline Management & $1446(21.1)$ & & 1369(6.4) & \\
\hline Other & $3038(35.1)$ & & $2895(10.4)$ & \\
\hline Total & $8030(28.2)$ & & $7609(10.3)$ & \\
\hline
\end{tabular}

women were all significantly higher than the national prevalence rates.

Table 1 also presents the results of bivariate crosstabulation of the support for continued FGM/C practice and the covariates considered. The proportion of women supporting the continuation of FGM/C at the time of the survey was surprisingly high and stood at 10.3\% (95\% CI: 8.4-12.4\%). We also found significant bivariate associations between most of the covariates considered and support for the continuation of FGM/C. There was no association between the woman's age and her support for the continuation of the practice. The proportion of circumcised women (30.0\%, 95\% CI: 25.4-35.0\%), supporting the continuation of the practice was considerably higher than that of uncircumcised women (2.4\%, 95\% CI: 25.4-35.0\%).

Support for the continuation of the practice was highest in the North Eastern (92.5\%, 95\% CI: 86.7-95.9\%) and Nyanza (20.1\%, 95\% CI: 14.1-27.7\%) provinces, where the practice is currently most prevalent.

\section{Spatial modelling and mapping}

In Table 2 we present the results of fitting the hierarchical models to the FGM/C data. Similar results for responses to the question "Should FGM/C continue" are presented in Table 3. Tables 2 and 3 also present the effective number of parameters, $p D$, and the Deviance Information Criterion $(D I C)$ for each of models entertained. Based on the DIC values, Model 3, the hierarchical model with spatially structured random effects was considered to be the best fitting model in each case.

The adjusted results suggest that all predictors considered, except the type of place of residence and the woman's occupation, were significantly associated with FGM/C status. The results suggested a linear increase in $\mathrm{FGM} / \mathrm{C}$ risk with age. We also found a linear decline in FGM/C risk with education, socioeconomic status and media exposure. The odds of women with primary education (AOR: 0.61, 95\% CI: 0.46 -0.81) having undergone FGM/C were 39\% lower than those for women with no formal education.
The risk of having undergone the cut declines further among better educated women. Women with secondary education (AOR: 0.30, 95\% CI: $0.21-0.41$ ) and those with tertiary education (AOR: 0.20, 95\% CI: 0.13 -0.31) were at $70 \%$ and $80 \%$ lower risk, respectively, of having undergone the cut compared to women with no formal education.

We also noted that women with high (AOR: 0.70, 95\% CI: 0.55 -0.90) and moderate (AOR: 0.89, 95\% CI: $0.73-1.07$ ) media exposure were at $30 \%$ and $11 \%$ lower risk respectively, of having undergone the procedure.

In terms of the response to the question concerning the continuation of the practice, all predictors except marital status, socioeconomic status and occupation were found to be significant. Women in the North Eastern province expressed greater support for the continuation of FGM/C compared to women from other provinces in Kenya. The results also suggest that women who had already undergone FGM/C were more likely to support the continuation of the practice compared to those women who had not (AOR: 10.96, 95\% CI: 8.34-14.50). We found a linear relationship between age and support for the continuation of FGM/C. The results however suggest that it is only women aged 40-44 years (AOR: 0.45, 95\% CI: 0.30-0.67) and 45-49 years (AOR: 0.48, 95\% CI: 0.32-0.71) who demonstrated significantly lower support for the continuation of FGM/C, compared to women aged 15-19 years. Support for the continuation of FGM/C was also much lower among women in urban areas (AOR: 0.66, 95\% CI: 0.490.88 ) compared to women in rural settings.

We also found significant linear decline in support for the continuation of the practice with education and media exposure.

\section{Spatial clustering of FGM/C Spatial clustering of women circumcised}

Table 4 presents the results of the spatial scan statistical analysis. A spatial scan statistic was applied to the aggregated county level data and identified six main high-risk FGM/C clusters. The first cluster $(R R=3.93, p<0.001)$ 
Table 2 Odds ratios, adjusted odds ratios and 95\% Credible Intervals (CI) for the association between FGM/C and the significant predictors

\begin{tabular}{|c|c|c|c|c|c|}
\hline \multirow[t]{2}{*}{ Variable } & \multirow[b]{2}{*}{ OR $(95 \% \mathrm{Cl})$} & \multirow{2}{*}{$\begin{array}{l}\text { Model } 1 \\
\text { AOR }(95 \% \mathrm{Cl})\end{array}$} & \multirow{2}{*}{$\begin{array}{l}\text { Model } 2 \\
\text { AOR }(95 \% \mathrm{Cl})\end{array}$} & \multirow{2}{*}{$\begin{array}{l}\text { Model } 3 \\
\text { AOR }(95 \% \mathrm{Cl})\end{array}$} & \multirow{2}{*}{$\begin{array}{l}\text { Model } 4 \\
\text { AOR }(95 \% \mathrm{Cl})\end{array}$} \\
\hline & & & & & \\
\hline \multicolumn{6}{|l|}{ Age } \\
\hline $15-19$ & 1.00 (Reference) & 1.00 (Reference) & 1.00 (Reference) & 1.00 (Reference) & 1.00 (Reference) \\
\hline $20-24$ & $1.11(0.94-1.30)$ & $1.36 *(1.08-1.72)$ & $1.60 *(1.20-2.14)$ & $1.60 *(1.20-2.14)$ & $1.60 *(1.20-2.14)$ \\
\hline $25-29$ & $1.53^{*}(1.30-1.80)$ & $1.84^{*}(1.43-2.36)$ & $2.34^{*}(1.72-3.19)$ & $2.36^{*}(1.73-3.22)$ & $2.34^{*}(1.72-3.19)$ \\
\hline $30-34$ & $1.71^{*}(1.45-2.03)$ & $2.27^{*}(1.73-2.94)$ & $3.06 *(2.20-4.22)$ & $3.06 *(2.23-4.22)$ & $3.06^{*}(2.20-4.22)$ \\
\hline $35-39$ & $2.21^{*}(1.85-2.63)$ & $2.69^{*}(2.03-3.56)$ & $4.01 *(2.89-5.58)$ & $4.01 *(2.89-5.64)$ & $4.01 *(2.89-5.58)$ \\
\hline $40-44$ & $2.48^{*}(2.06-3.00)$ & $3.63^{*}(2.72-4.85)$ & $5.75 *(4.06-8.25)$ & $5.75^{*}(4.06-8.25)$ & $5.75^{*}(4.06-8.25)$ \\
\hline $45-49$ & $3.13^{*}(2.58-3.80)$ & $4.44^{*}(3.32-5.93)$ & $7.69^{*}(5.37-11.02)$ & $7.69 *(5.37-11.02)$ & $7.69^{*}(5.37-11.02)$ \\
\hline \multicolumn{6}{|l|}{ Region } \\
\hline North Eastern & 1.00 (Reference) & 1.00 (Reference) & 1.00 (Reference) & 1.00 (Reference) & 1.00 (Reference) \\
\hline Central & $0.00 *(0.00-0.01)$ & $0.05^{*}(0.02-0.09)$ & $0.02^{*}(0.00-0.32)$ & $0.04^{*}(0.00-3.42)$ & $0.02 *(0.00-0.33)$ \\
\hline Coast & $0.01^{*}(0.00-0.01)$ & $0.01 *(0.00-0.01)$ & $0.00 *(0.00-0.03)$ & $0.01^{*}(0.00-0.30)$ & $0.00^{*}(0.00-0.03)$ \\
\hline Eastern & $0.00 *(0.00-0.01)$ & $0.07^{*}(0.04-0.13)$ & $0.04^{*}(0.00-0.61)$ & $0.04^{*}(0.00-1.80)$ & $0.04^{*}(0.00-0.63)$ \\
\hline Nairobi & $0.02 *(0.01-0.03)$ & $0.03^{*}(0.01-0.05)$ & $0.01 *(0.00-1.21)$ & $0.02 *(0.00-9.58)$ & $0.01^{*}(0.00-1.25)$ \\
\hline Nyanza & $0.01 *(0.01-0.02)$ & $0.06^{*}(0.03-0.10)$ & $0.02^{*}(0.00-0.35)$ & $0.03^{*}(0.00-4.10)$ & $0.02 *(0.00-0.35)$ \\
\hline Rift Valley & $0.01 *(0.01-0.02)$ & $0.07^{*}(0.04-0.12)$ & $0.02^{*}(0.00-0.30)$ & $0.03^{*}(0.00-2.69)$ & $0.02 *(0.00-0.31)$ \\
\hline Western & $0.00 *(0.00-0.00)$ & $0.00 *(0.00-0.00)$ & $0.00^{*}(0.00-0.01)$ & $0.00 *(0.00-0.59)$ & $0.00 *(0.00-0.01)$ \\
\hline \multicolumn{6}{|l|}{ Type of place of residence } \\
\hline Urban & 1.00 (Reference) & 1.00 (Reference) & 1.00 (Reference) & 1.00 (Reference) & 1.00 (Reference) \\
\hline Rural & $2.40 *(2.14-2.68)$ & $0.98(0.79-1.22)$ & 0.90(0.68-1.19) & $0.90(0.68-1.19)$ & 0.90(0.68-1.19) \\
\hline \multicolumn{6}{|l|}{ Education } \\
\hline No formal & 1.00 (Reference) & 1.00 (Reference) & 1.00 (Reference) & 1.00 (Reference) & 1.00 (Reference) \\
\hline Primary & $0.15^{*}(0.13-0.18)$ & $0.58^{*}(0.46-0.73)$ & $0.61^{*}(0.45-0.80)$ & $0.61^{*}(0.46-0.81)$ & $0.61^{*}(0.45-0.80)$ \\
\hline Secondary & $0.09^{*}(0.08-0.11)$ & $0.44^{*}(0.34-0.57)$ & $0.30^{*}(0.21-0.41)$ & $0.30 *(0.21-0.41)$ & $0.30^{*}(0.21-0.41)$ \\
\hline Higher & $0.06^{*}(0.04-0.07)$ & $0.32 *(0.23-0.46)$ & $0.20^{*}(0.13-0.31)$ & $0.20^{*}(0.13-0.31)$ & $0.20^{*}(0.13-0.31)$ \\
\hline \multicolumn{6}{|l|}{ Marital status } \\
\hline Never Married & 1.00 (Reference) & 1.00 (Reference) & 1.00 (Reference) & 1.00 (Reference) & 1.00 (Reference) \\
\hline Married, living together & $2.36^{*}(2.10-2.65)$ & $1.38 *(1.14-1.65)$ & $1.65 *(1.31-2.05)$ & $1.63^{*}(1.31-2.05)$ & $1.65^{*}(1.31-2.05)$ \\
\hline Separated & $1.90 *(1.59-2.27)$ & 0.95(0.73-1.23) & $1.30(0.96-1.75)$ & $1.30(0.96-1.75)$ & $1.30(0.96-1.75)$ \\
\hline \multicolumn{6}{|l|}{ Religion } \\
\hline Muslim & 1.00 (Reference) & 1.00 (Reference) & 1.00 (Reference) & 1.00 (Reference) & 1.00 (Reference) \\
\hline Roman Catholic & $0.26^{*}(0.22-1.00)$ & $0.24^{*}(0.18-0.32)$ & $0.17 *(0.12-0.25)$ & $0.18^{*}(0.12-0.25)$ & $0.17^{*}(0.12-0.25)$ \\
\hline Other Christian & $0.17^{*}(0.15-0.19)$ & $0.20^{*}(0.15-0.27)$ & $0.13^{*}(0.09-0.18)$ & $0.13^{*}(0.09-0.19)$ & $0.13^{*}(0.09-0.18)$ \\
\hline No religion & $0.39 *(0.28-0.56)$ & $0.31^{*}(0.19-0.49)$ & $0.20^{*}(0.11-0.36)$ & $0.20^{*}(0.11-0.37)$ & $0.20^{*}(0.11-0.36)$ \\
\hline Other & $0.06^{*}(0.02-0.14)$ & $0.04^{*}(0.01-0.13)$ & $0.03^{*}(0.01-0.10)$ & $0.03^{*}(0.01-0.10)$ & $0.03^{*}(0.01-0.10)$ \\
\hline \multicolumn{6}{|l|}{ Socioeconomic status } \\
\hline Poorest & 1.00 (Reference) & 1.00 (Reference) & 1.00 (Reference) & 1.00 (Reference) & 1.00 (Reference) \\
\hline Poorer & $0.42^{*}(0.36-0.50)$ & $1.08(0.88-1.34)$ & $0.97(0.75-1.26)$ & $0.98(0.75-1.27)$ & $0.97(0.75-1.26)$ \\
\hline Middle & $0.37^{*}(0.32-0.43)$ & 0.88(0.71-1.08) & $0.80(0.61-1.04)$ & $0.81(0.62-1.05)$ & $0.80(0.61-1.04)$ \\
\hline Richer & $0.31^{*}(0.27-0.36)$ & $0.78^{*}(0.63-0.98)$ & $0.71 *(0.54-0.95)$ & $0.72 *(0.54-0.95)$ & $0.71^{*}(0.54-0.95)$ \\
\hline Richest & $0.17^{*}(0.15-0.20)$ & $0.66^{*}(0.50-0.89)$ & $0.64^{*}(0.44-0.92)$ & $0.64^{*}(0.44-0.92)$ & $0.64 *(0.44-0.92)$ \\
\hline
\end{tabular}


Table 2 Odds ratios, adjusted odds ratios and 95\% Credible Intervals (CI) for the association between FGM/C and the significant predictors (Continued)

\begin{tabular}{|c|c|c|c|c|c|}
\hline \multicolumn{6}{|l|}{ Media exposure } \\
\hline low & 1.00 (Reference) & 1.00 (Reference) & 1.00 (Reference) & 1.00 (Reference) & 1.00 (Reference) \\
\hline mid & $0.35^{*}(0.31-0.40)$ & $0.67^{*}(0.58-0.79)$ & $0.89(0.73-1.07)$ & $0.89(0.73-1.07)$ & $0.89(0.73-1.07)$ \\
\hline high & $0.20 *(0.17-0.22)$ & $0.60 *(0.49-0.73)$ & $0.70^{*}(0.55-0.90)$ & $0.70 *(0.55-0.90)$ & $0.70^{*}(0.55-0.90)$ \\
\hline \multicolumn{6}{|l|}{ Occupation } \\
\hline Not working & 1.00 (Reference) & 1.00 (Reference) & 1.00 (Reference) & 1.00 (Reference) & 1.00 (Reference) \\
\hline management & $0.59^{*}(0.51-0.68)$ & $0.83(0.68-1.00)$ & $0.93(0.74-1.17)$ & $0.93(0.74-1.17)$ & $0.93(0.74-1.17)$ \\
\hline Other & $0.92(0.83-1.02)$ & $1.07(0.92-1.23)$ & $1.07(0.90-1.28)$ & $1.07(0.90-1.28)$ & $1.07(0.90-1.28)$ \\
\hline \multicolumn{6}{|l|}{ Random Effect } \\
\hline Unstructured $\left(\tau_{u}\right)$ & & & $0.25(0.15-0.40)$ & & $0.25(0.15-0.40)$ \\
\hline Structured $\left(\tau_{s}\right)$ & & & & $0.06(0.04-0.10)$ & $13910(1416-73690)$ \\
\hline $\mathrm{DIC}$ & & 6889.79 & 5144.13 & 5142.92 & 5144.23 \\
\hline $\mathrm{pD}$ & & 31.84 & 68.54 & 68.2 & 68.59 \\
\hline
\end{tabular}

${ }^{*} p<0.05$.

identified consisted of 779 (257.64 expected) cases in six counties. This cluster consisted of Mandera, Wajir, Marsabit, Isiolo, Garissa and Samburu counties. The second significant cluster $(\mathrm{RR}=2.97, \mathrm{p}<0.001)$ identified consisted of 474 (182.09 expected) cases in four counties namely, Bomet, Nyamira, Kisii and Narok and the third cluster with 109 (61.01 expected) cases, with a relative risk of 1.82 ( $\mathrm{p}<0.001$ ), consisted of Kitui county. These clusters are in regions inhabited by the Somali, Kisii, Maasai, Kuria and Meru ethnic communities.

Two low-risk clusters were identified. The main low-risk cluster, with a relative risk of $0.06(\mathrm{p}<0.001)$, consisted of counties in Western and Nyanza provinces whereas the secondary cluster identified, with a relative risk of 0.48 ( $p<0.001$ ), consisted of counties in the Coast and Eastern provinces.

\section{Spatial clustering of support for the continuation of FGM}

With regards to support for the continuation of FGM/C, two significant clusters were identified. This first cluster $(\mathrm{RR}=12.80, \mathrm{p}<0.001)$ identified consisted of $702(54.84$ expected) cases in five counties. This cluster consisted of Mandera, Wajir, Marsabit, Isiolo, and Garissa counties. The next significant cluster $(R R=2.58, \mathrm{p}<0.001)$ identified consisted of 153 (59.37 expected) cases in two counties namely Kisii and Nyamira. These clusters are in regions inhabited by the Somali, Kisii, and Meru ethnic communities.

\section{Spatial mapping}

Figure 1 presents relative risk maps of FGM/C and of prevalence of support for the continuation of FGM. It is apparent from these maps that FGM/C 'hotspots' are in the North Eastern and South Western regions of the country.
Figure 2 presents smoothed FGM/C risk maps for Kenya that arose from fitting the hierarchical spatial model with a spatially structured random effect to the data. It is apparent yet again that the North Eastern and South Western regions of the country bear the greatest FGM/C burden.

In Figure 3 we present a smoothed map of the prevalence of support for FGM/C in Kenya. This map also supports the results of the spatial cluster analysis.

\section{Discussion}

This study used a Bayesian hierarchical spatial modelling approach to investigate the spatial variation in the risk and intention to continue the practice of FGM/C in Kenya. As opposed to a more standard Markov Chain Monte Carlo approach, we employed an Integrated Nested laplace algorithm within the R library INLA to fit Besag, York and Mollie [45] like models. The Kulldorff spatial scan statistic was used for cluster detection and to test for local clusters of FGM/C. The results of the spatial scan statistical analysis supported and confirmed the results of the findings of the Bayesian hierarchical analysis.

The study has demonstrated both geographical heterogeneity in the practice, and support for the continued practice of FGM/C in Kenya. The counties located in the North Eastern and South Western parts of the country are identified as FGM 'hotspots' and are areas in need of urgent attention. These findings reveal the enormity of the task faced by the Government of Kenya, in support of initiatives by World Health Organization (WHO), to outlaw the practice in the country [1].

This study finds a linear negative relationship between a woman's level of education and the view that FGM/C should continue. Similar results have been reported elsewhere $[21,24,32]$ and are consistent with modernization 
Table 3 Odds ratios, Adjusted Odds ratios and 95\% Credible Intervals (CI) for the association between Continued FGM/C and the significant predictors

\begin{tabular}{|c|c|c|c|c|c|}
\hline \multirow[t]{2}{*}{ Variable } & \multirow[b]{2}{*}{ OR $(95 \%$ Cl) } & \multirow{2}{*}{$\begin{array}{l}\text { Model } 1 \\
\text { AOR }(95 \% \mathrm{Cl})\end{array}$} & \multirow{2}{*}{$\begin{array}{l}\text { Model } 2 \\
\text { AOR }(95 \% \mathrm{Cl})\end{array}$} & \multirow{2}{*}{$\begin{array}{l}\text { Model } 3 \\
\text { AOR }(95 \% \mathrm{Cl})\end{array}$} & \multirow{2}{*}{$\begin{array}{l}\text { Model } 4 \\
\text { AOR }(95 \% \mathrm{Cl})\end{array}$} \\
\hline & & & & & \\
\hline \multicolumn{6}{|l|}{ Circumcised } \\
\hline No & 1.00 (Reference) & 1.00 (Reference) & 1.00 (Reference) & 1.00 (Reference) & 1.00 (Reference) \\
\hline Yes & $29.67 *(24.78-35.87)$ & $10.5^{*}(8.02-13.89)$ & $10.5^{*}(8.01-13.88)$ & $10.2^{*}(7.82-13.52)$ & $10.53 *(8.02-10.52)$ \\
\hline \multicolumn{6}{|l|}{ Age } \\
\hline $15-19$ & 1.00 (Reference) & 1.00 (Reference) & 1.00 (Reference) & 1.00 (Reference) & 1.00 (Reference) \\
\hline $20-24$ & $0.95(0.79-1.15)$ & $1.00(0.72-1.41)$ & $1.00(0.72-1.41)$ & $1.00(0.72-1.41)$ & $1.00(0.72-1.00)$ \\
\hline $25-29$ & $0.96(0.79-1.17)$ & $0.69(0.48-1.01)$ & $0.69(0.48-1.01)$ & $0.70(0.48-1.01)$ & $0.69(0.48-0.69)$ \\
\hline $30-34$ & $0.78(0.63-0.96)$ & $0.63^{*}(0.42-0.95)$ & $0.63^{*}(0.42-0.95)$ & $0.64^{*}(0.42-0.96)$ & $0.63^{*}(0.42-0.63)$ \\
\hline $35-39$ & $1.07(0.85-1.32)$ & $0.66(0.43-1.00)$ & $0.66(0.43-1.00)$ & $0.66(0.43-1.00)$ & $0.66(0.43-0.66)$ \\
\hline $40-44$ & $0.82(0.63-1.05)$ & $0.40 *(0.25-0.62)$ & $0.40^{*}(0.25-0.63)$ & $0.40^{*}(0.25-0.63)$ & $0.40^{*}(0.25-0.40)$ \\
\hline $45-49$ & $0.93(0.72-1.20)$ & $0.44^{*}(0.28-0.68)$ & $0.44^{*}(0.28-0.68)$ & $0.44^{*}(0.28-0.69)$ & $0.44^{*}(0.28-0.44)$ \\
\hline \multicolumn{6}{|l|}{ Region } \\
\hline North Eastern & 1.00 (Reference) & 1.00 (Reference) & 1.00 (Reference) & 1.00 (Reference) & 1.00 (Reference) \\
\hline Central & $0.00 *(0.00-0.01)$ & $0.07^{*}(0.02-0.22)$ & $0.07^{*}(0.02-0.22)$ & $0.16^{*}(0.03-0.95)$ & $0.07^{*}(0.02-0.07)$ \\
\hline Coast & $0.00 *(0.00-0.01)$ & $0.03 *(0.01-0.09)$ & $0.03^{*}(0.01-0.09)$ & $0.08^{*}(0.02-0.38)$ & $0.03 *(0.01-0.03)$ \\
\hline Eastern & $0.02^{*}(0.01-0.03)$ & $0.10^{*}(0.03-0.29)$ & $0.10^{*}(0.03-0.29)$ & $0.20^{*}(0.05-0.84)$ & $0.10^{*}(0.03-0.10)$ \\
\hline Nairobi & $0.00^{*}(0.00-0.01)$ & $0.10^{*}(0.02-0.57)$ & $0.10^{*}(0.02-0.56)$ & $0.16^{*}(0.02-1.51)$ & $0.10^{*}(0.02-0.10)$ \\
\hline Nyanza & $0.02^{*}(0.01-0.03)$ & $0.19 *(0.06-0.58)$ & $0.19^{*}(0.06-0.58)$ & $0.81^{*}(0.11-5.98)$ & $0.19^{*}(0.06-0.19)$ \\
\hline Rift Valley & $0.01 *(0.00-0.01)$ & $0.04^{*}(0.01-0.10)$ & $0.04^{*}(0.01-0.10)$ & $0.12^{*}(0.02-0.67)$ & $0.04^{*}(0.01-0.04)$ \\
\hline Western & $0.00^{*}(0.00-0.00)$ & $0.05^{*}(0.01-0.17)$ & $0.05^{*}(0.01-0.17)$ & $0.22^{*}(0.03-1.98)$ & $0.05^{*}(0.01-0.05)$ \\
\hline \multicolumn{6}{|l|}{ Type of place of residence } \\
\hline Urban & 1.00 (Reference) & 1.00 (Reference) & 1.00 (Reference) & 1.00 (Reference) & 1.00 (Reference) \\
\hline Rural & $2.39 *(2.14-2.69)$ & $0.65^{*}(0.44-0.94)$ & $0.65^{*}(0.44-0.94)$ & $0.65^{*}(0.45-0.95)$ & $0.65^{*}(0.44-0.65)$ \\
\hline \multicolumn{6}{|l|}{ Education } \\
\hline No formal & 1.00 (Reference) & 1.00 (Reference) & 1.00 (Reference) & 1.00 (Reference) & 1.00 (Reference) \\
\hline Primary & $0.07^{*}(0.06-0.08)$ & $0.42 *(0.31-0.57)$ & $0.42^{*}(0.31-0.57)$ & $0.43^{*}(0.32-0.58)$ & $0.42^{*}(0.31-0.42)$ \\
\hline Secondary & $0.05^{*}(0.04-0.06)$ & $0.34^{*}(0.24-0.50)$ & $0.34^{*}(0.24-0.50)$ & $0.35^{*}(0.24-0.52)$ & $0.34^{*}(0.24-0.34)$ \\
\hline Higher & $0.02^{*}(0.01-0.03)$ & $0.18 *(0.10-0.33)$ & $0.18^{*}(0.10-0.33)$ & $0.19^{*}(0.10-0.34)$ & $0.18^{*}(0.10-0.18)$ \\
\hline \multicolumn{6}{|l|}{ Marital status } \\
\hline Never Married & 1.00 (Reference) & 1.00 (Reference) & 1.00 (Reference) & 1.00 (Reference) & 1.00 (Reference) \\
\hline Married, living together & $1.67^{*}(1.45-1.93)$ & $1.40 *(1.04-1.89)$ & $1.40^{*}(1.04-1.89)$ & $1.40 *(1.04-1.89)$ & $1.40 *(1.04-1.40)$ \\
\hline Separated & $1.15(0.90-1.46)$ & $1.50(0.99-2.25)$ & $1.50(0.99-2.25)$ & $1.50(0.99-2.25)$ & $1.50(0.99-1.50)$ \\
\hline \multicolumn{6}{|l|}{ Religion } \\
\hline Muslim & 1.00 (Reference) & 1.00 (Reference) & 1.00 (Reference) & 1.00 (Reference) & 1.00 (Reference) \\
\hline Roman Catholic & $0.09^{*}(0.07-0.11)$ & $0.64^{*}(0.43-0.97)$ & $0.64^{*}(0.43-0.97)$ & $0.65^{*}(0.43-0.98)$ & $0.64^{*}(0.43-0.64)$ \\
\hline Other Christian & $0.06^{*}(0.05-0.07)$ & $0.49 *(0.33-0.73)$ & $0.49^{*}(0.33-0.73)$ & $0.49^{*}(0.33-0.73)$ & $0.49^{*}(0.33-0.49)$ \\
\hline No religion & $0.31^{*}(0.21-0.46)$ & $1.95 *(1.04-3.63)$ & $1.95^{*}(1.04-3.63)$ & $1.99 *(1.07-3.69)$ & $1.95^{*}(1.04-1.95)$ \\
\hline Other & $0.09(0.03-0.22)$ & 1.37(0.30-4.81) & $1.37(0.30-4.82)$ & $1.39(0.30-4.86)$ & $1.32(0.30-1.37)$ \\
\hline \multicolumn{6}{|l|}{ Socioeconomic status } \\
\hline Poorest & 1.00 (Reference) & 1.00 (Reference) & 1.00 (Reference) & 1.00 (Reference) & 1.00 (Reference) \\
\hline Poorer & $0.25^{*}(0.20-0.30)$ & $0.92(0.67-1.27)$ & $0.92(0.67-1.27)$ & $0.93(0.68-1.27)$ & $0.92(0.67-0.92)$ \\
\hline Middle & $0.22(0.18-0.27)$ & $1.17(0.85-1.63)$ & $1.17(0.85-1.63)$ & $1.18(0.85-1.63)$ & $1.17(0.85-1.17)$ \\
\hline
\end{tabular}


Table 3 Odds ratios, Adjusted Odds ratios and 95\% Credible Intervals (CI) for the association between Continued FGM/C and the significant predictors (Continued)

\begin{tabular}{|c|c|c|c|c|c|}
\hline Richer & $0.18(0.15-0.22)$ & $0.87(0.61-1.25)$ & $0.87(0.61-1.25)$ & $0.87(0.61-1.25)$ & $0.87(0.61-0.87)$ \\
\hline Richest & $0.13(0.11-0.15)$ & $0.83(0.51-1.36)$ & $0.83(0.51-1.36)$ & $0.84(0.51-1.37)$ & $0.83(0.51-0.83)$ \\
\hline \multicolumn{6}{|l|}{ Media Exposure } \\
\hline low & 1.00 (Reference) & 1.00 (Reference) & 1.00 (Reference) & 1.00 (Reference) & 1.00 (Reference) \\
\hline mid & $0.12^{*}(0.10-0.15)$ & $0.84(0.66-1.07)$ & $0.84(0.66-1.07)$ & $0.85(0.67-1.08)$ & $0.84^{*}(0.66-0.84)$ \\
\hline high & $0.21^{*}(0.18-0.24)$ & $0.68^{*}(0.50-0.93)$ & $0.68 *(0.50-0.93)$ & $0.68 *(0.50-0.93)$ & $0.68^{*}(0.50-0.68)$ \\
\hline \multicolumn{6}{|l|}{ Occupation } \\
\hline Not working & 1.00 (Reference) & 1.00 (Reference) & 1.00 (Reference) & 1.00 (Reference) & 1.00 (Reference) \\
\hline management & $0.32^{*}(0.30-0.35)$ & $0.81(0.59-1.11)$ & $0.81(0.59-1.11)$ & $0.82(0.59-1.12)$ & $0.81^{*}(0.59-0.81)$ \\
\hline Other & $0.32 *(0.26-0.39)$ & $0.83(0.66-1.05)$ & $0.83(0.66-1.05)$ & $0.84(0.66-1.06)$ & $0.83^{*}(0.66-0.83)$ \\
\hline \multicolumn{6}{|l|}{ Random Effect } \\
\hline Unstructured $\left(t_{u}\right)$ & & & $1.97(1.05-3.63)$ & & $1.97(1.05-3.63)$ \\
\hline Structured $\left(t_{s}\right)$ & & & & $0.52(0.27-1.01)$ & 13850(1399-73250) \\
\hline $\mathrm{DIC}$ & & 3489.83 & 3363.04 & 3361.83 & 3363.36 \\
\hline $\mathrm{pD}$ & & 32.61 & 59.75 & 58.29 & 59.89 \\
\hline
\end{tabular}

${ }^{*} p<0.05$.

Table 4 Statistically significant high-risk clusters

\begin{tabular}{|c|c|c|c|c|c|}
\hline Outcome & Type & & $\begin{array}{l}\text { Observed } \\
\text { (Expected) cases }\end{array}$ & $\begin{array}{l}\text { Relative risk } \\
\text { (p-value) }\end{array}$ & Counties \\
\hline \multirow[t]{8}{*}{$\begin{array}{l}\text { Woman } \\
\text { circumcised }\end{array}$} & $\begin{array}{l}\text { High risk } \\
\text { cluster }\end{array}$ & $\begin{array}{l}\text { Most likely } \\
\text { cluster }\end{array}$ & $779(257.64)$ & $3.92(<0.001)$ & Mandera, Wajir, Marsabit, Isiolo, Garissa, Samburu \\
\hline & & $\begin{array}{l}\text { Secondary } \\
\text { cluster }\end{array}$ & $474(182.09)$ & $2.97(<0.001)$ & Bomet, Nyamira, Kisii, Narok \\
\hline & & $\begin{array}{l}\text { Third most } \\
\text { likely cluster }\end{array}$ & $109(61.01)$ & $1.82(<0.001)$ & Kitui \\
\hline & & $\begin{array}{l}\text { Fourth most } \\
\text { likely cluster }\end{array}$ & $52(25.29)$ & $2.08(<0.001)$ & Baringo \\
\hline & & $\begin{array}{l}\text { Fifth most likely } \\
\text { cluster }\end{array}$ & $29(12.96)$ & $2.25(<0.001)$ & WestPokot \\
\hline & & $\begin{array}{l}\text { Sixth most } \\
\text { likely cluster }\end{array}$ & $205(154.90)$ & $1.35(0.02)$ & Meru, Tharaka-Nithi, Embu \\
\hline & $\begin{array}{l}\text { Low risk } \\
\text { cluster }\end{array}$ & $\begin{array}{l}\text { Most likely } \\
\text { cluster }\end{array}$ & 45(558.91) & $0.064(<0.001)$ & Busia, Siaya, Kakamega, Bungoma, Vihiga, Kisumu, Nandi, HomaBay \\
\hline & & $\begin{array}{l}\text { Secondary } \\
\text { cluster }\end{array}$ & $488(844.68)$ & $0.48(<0.001)$ & $\begin{array}{l}\text { Taita Taveta, Kwale, Kilifi, Mombasa, Makueni, Kitui, Kajiado, Tana } \\
\text { River, Machakos, Nairobi, Lamu, Kiambu }\end{array}$ \\
\hline \multirow[t]{4}{*}{$\begin{array}{l}\text { FGM/C should } \\
\text { continue }\end{array}$} & $\begin{array}{l}\text { High risk } \\
\text { cluster }\end{array}$ & $\begin{array}{l}\text { Most likely } \\
\text { cluster }\end{array}$ & $702(54.84)$ & $12.80(<0.001)$ & Mandera, Wajir, Marsabit, Isiolo, Garissa \\
\hline & & $\begin{array}{l}\text { Secondary } \\
\text { cluster }\end{array}$ & 153(59.37) & $2.58(<0.001)$ & Kisii, Nyamira \\
\hline & $\begin{array}{l}\text { Low risk } \\
\text { cluster }\end{array}$ & $\begin{array}{l}\text { Most likely } \\
\text { cluster }\end{array}$ & 18(166.31) & $0.08(<0.001)$ & $\begin{array}{l}\text { Kakamega, Vihiga, Bungoma, Nandi, Busia, Kisumu, Uasin Gishu, } \\
\text { Siaya, Trans Nzoia, Kericho, Elgeyo Marakwet, HomaBay }\end{array}$ \\
\hline & & $\begin{array}{l}\text { Secondary } \\
\text { cluster }\end{array}$ & $66(218.94)$ & $0.20(<0.001)$ & $\begin{array}{l}\text { TaitaTaveta, Kwale, Kilifi, Mombasa, Makueni, Kitui, Kajiado, TanaRiver, } \\
\text { Machakos, Nairobi, Lamu, Kiambu, Embu, Muranga, Kirinyaga, } \\
\text { Tharaka-Nithi, Nyeri }\end{array}$ \\
\hline
\end{tabular}



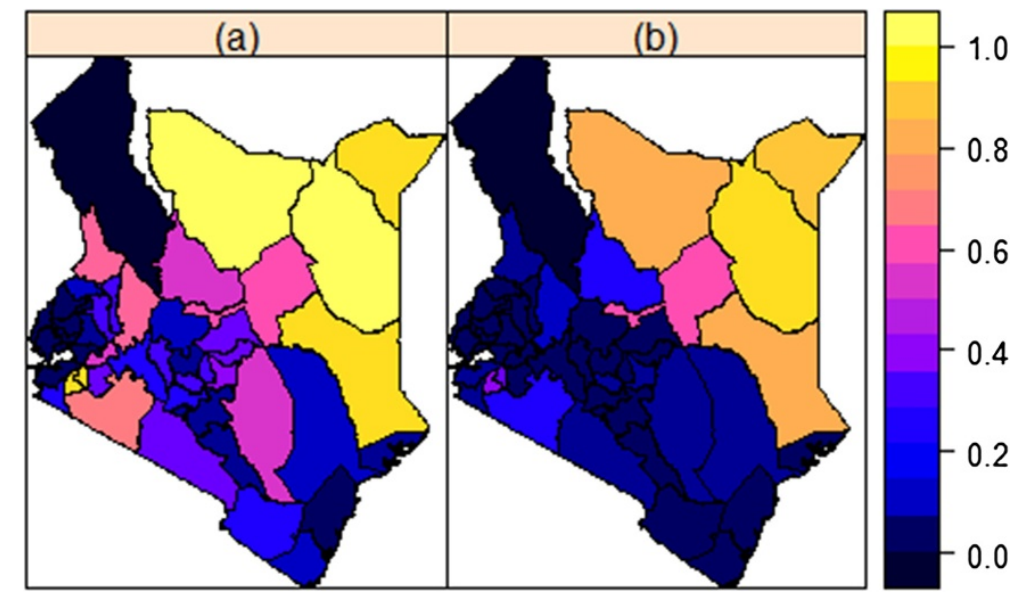

Figure 1 Observed (Crude) county level prevalence maps. (a) Prevalence of FGM/C. (b) Proportion of women in support of FGM/C continuation.
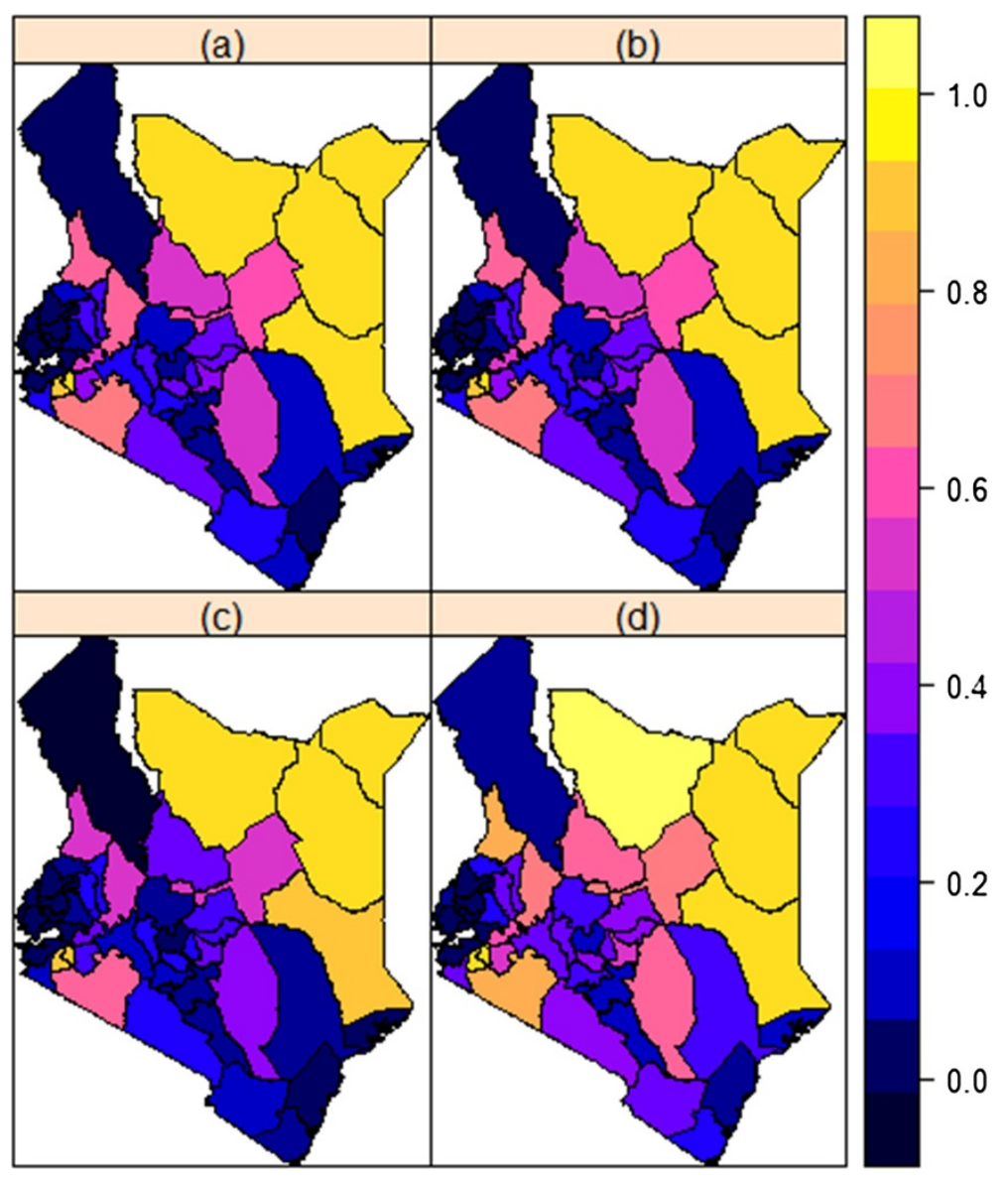

Figure 2 Prevalence of FGM/C predicted from the parsimonious spatial model. (a) Mean posterior prevalence rates. (b) Median posterior prevalence rates. (c) $2.5 \%$ posterior prevalence rates. (d) $97.5 \%$ posterior prevalence rates. 


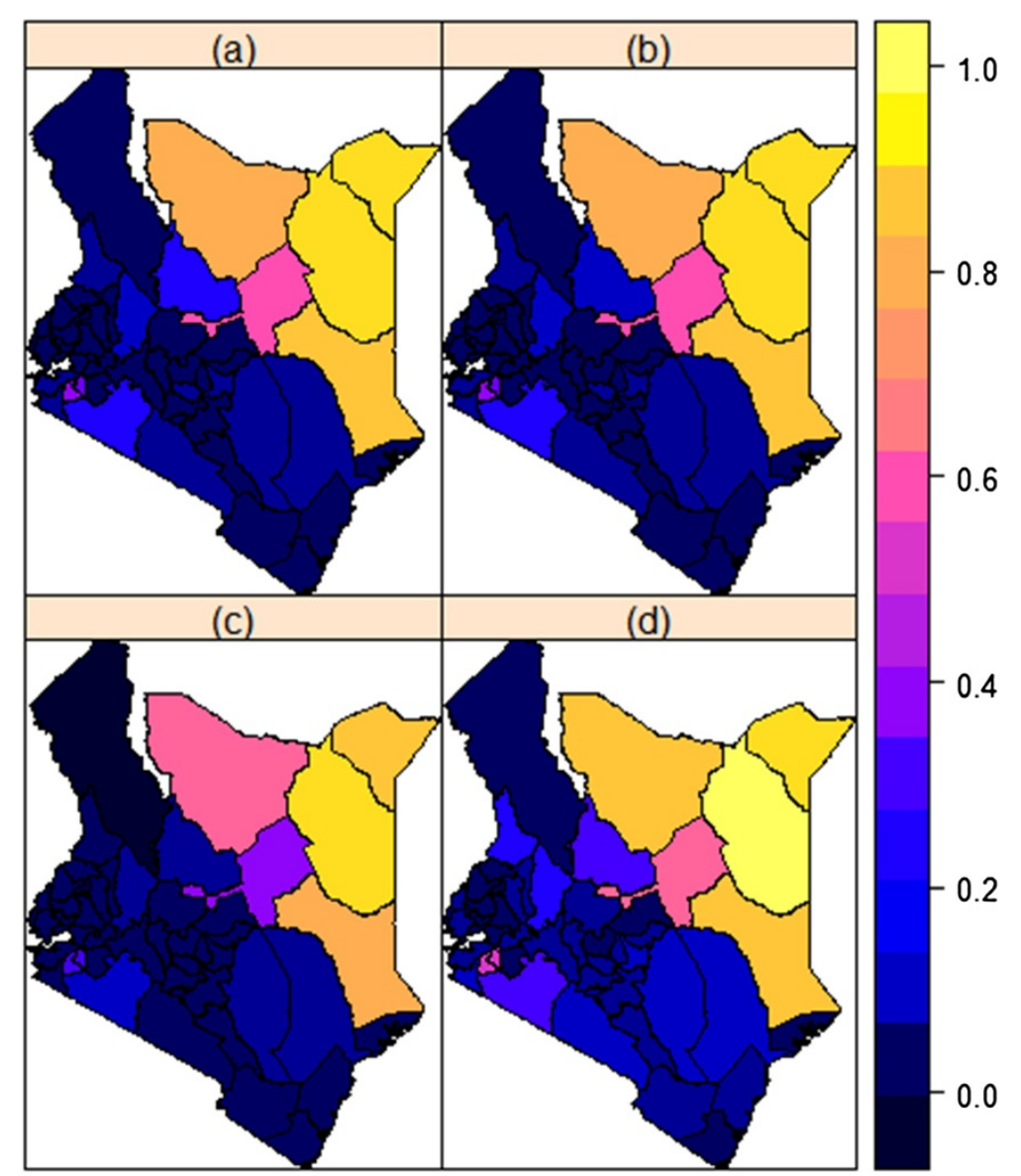

Figure 3 Prevalence of support for FGM/C continuation predicted from the parsimonious spatial model. (a) Mean posterior prevalence rates. (b) Median posterior prevalence rates. (c) $2.5 \%$ posterior prevalence rates. (d) $97.5 \%$ posterior prevalence rates.

theory that argues that education transmits Western ideals, in particular individual rights and the importance of health [21], thereby empowering women to make informed decisions concerning their well-being. The results are also consistent with the content aspect of conventional theory where educated women are considered more likely to learn about the negative consequences of female genital cutting and are therefore less likely to support its continuation [24,27]. As a consequence educated women are better able to make decisions and to seek alternative opportunities for their daughters.

As indicated in other studies in the literature, the decision to have one's child circumcised is never the prerogative of the woman alone and is in most settings driven by societal, household, husband and family considerations $[24,30,46]$. Initial results from the study suggest that women who are better educated possibly have a greater say in the health issues that affect their families, and are less likely to support the continuation of the practice, compared to those whose husband or others have made the decisions regarding the family's health. A limitation of this study stems from the fact that the DHS data contained limited information about the role of household members in decisions concerning female genital mutilation. This study therefore, does not fully account for the decision making dynamics within households.

The results of the study indicate high prevalence and clusters of the practice in counties within the North Eastern province of Kenya, bordering Somalia and Ethiopia, parts of South Nyanza, near Lake Victoria, and in parts of the Eastern province. The study also adds to the general body of knowledge on the subject of women's support for FGM/C by documenting and mapping prevalence and identifying high-risk clusters. The fact that there were no high-risk clusters in support of the continuation of FGM/C in those communities with a current high prevalence of $\mathrm{FGM} / \mathrm{C}$, needs mentioning. The study did not find significant clusters of support for the continuation of FGM/C in counties where the Meru (Meru North, Tharaka), Kikuyu (Muranga, Thika, Kirinyaga, Kiambu County), Kamba (Mwingi county) and Taita (Taita/Taveta county) ethnic groups live. This, as noted by others [24], suggests a possible decline, or eradication of the practice 
amongst these communities. There is a need to carry out a spatio-temporal analysis to confirm this assertion. The relationship between ethnicity and FGM/C is however quite complex and the break from, or maintenance of, traditional behaviours requires further investigation $[24,47]$.

The cause of FGM/C has been explained as a mix of cultural, religious and social factors $[26,29,31]$. It is considered an obligatory social and traditional norm aimed at maintaining virginity and sexual chastity, and the reduction and control of female sexuality $[3,25,28]$. Controversial and safer clinical approaches have been suggested and are practiced in many communities worldwide in the hope that these positive approaches rather than censorious ones may lead to a more rapid decline in FGM/C prevalence [48]. Current strategies geared towards reduction in FGM/C prevalence are shifting from the more clinical and health risk approaches to models that seek to address the phenomena within its social context. Communities in Kenya, and other countries across the globe where FGM/C is rampant, are structured along patriarchal systems that control both sexuality and fertility [49]. The social pressure to conform has been identified as a strong motivator in perpetuating the practice [23]. It is often considered a necessary part of raising a girl properly, and a way of preparing her for adulthood and marriage, influenced by beliefs linking the procedures to premarital virginity and marital fidelity. Although there exists no religious scripts that prescribe the practice, practitioners often believe the practice has religious support [50,51]. The results of this study indicated clustering of FGM/C in the North Eastern province of Kenya where Islam is a dominant religion. As with the other FGM/C clusters identified, the practice was prevalent is regions with poor access to basic education, extreme poverty, and low media exposure [52,53]. There is evidence based on our findings that FGM/C continues unabated in sparsely populated and remote regions that are quite isolated from the rest of the country and given low priority in national development efforts.

In Kenya, the practice was nearly universal among the Kisii and Maasai and very common among Kalenjin, Taita/Taveta, Embu/Mere, and to a lesser extent among the Kikuyu, Kamba, and Mjikenda/Swahili [54]. Our results concur with these finding but also indicate a possible high prevalence of the practice amongst the Somali, Rendile, Borana and Oromo community in North Eastern Province, Kenya. FGM/C is however not practiced among some ethnic groups in the country, notably the Luo, Luhya, Teso and Turkana.

Although the political and legal environment in Kenya has been hostile towards the practice, the results of this study indicate that it will take a great effort to see a substantial and sustainable change in the prevalence of the practice in certain regions and sectors. Despite the defeat in parliament of a motion to outlaw some forms of FGM/C in 1996, the Kenyan government formally outlawed the practice by passing the 2001 Children's Bill [55].

Numerous FGM/C abandonment interventions have been proposed in the literature. Each intervention was designed to address a given context and target factors (tradition, religion and reduction in female sexual desire) assumed to support the continuation of FGM. These included human rights based approaches, public declarations, legislative mechanisms, alternative rites of passage, national and regional workshops, training and conversion of circumcisers, training of trainer workshops and comprehensive social development processes [56-59]. The rates of success of these interventions have varied significantly, based on context and whether they are perceived by communities to respect socio-cultural values and settings. Efforts to eradicate the practice in Kenya must target the high-risk FGM/C clusters identified in this study, but also need to effectively involve community, religious and political leaders in order to achieve meaningful change.

\section{Conclusions}

The fight against FGM/C in Kenya is not over. There are still deep cultural and religious beliefs alongside illiteracy that have made it difficult to completely eradicate the practice. Interventions by government and other stakeholders must address these challenges and target the clusters identified in this study in order to achieve the goals set out by the Committee on the Elimination of all Forms of Discrimination against Women. The education of the girl child, along with empowerment to make informed decisions on personal health, must be given priority in the regions identified and in the nation as a whole.

\section{Consent}

Informed consent of the respondent was obtained for the survey at the start of the individual interview. A standard consent form approved by the Scientific and Ethical Review Committee of the Kenya Medical Research Institute (KEMRI) and by the Ethics Committee of the Opinion Research Corporation Macro International Incorporated (ORC Macro Inc.), Calverton, USA was read to the respondent in their native language. Once the respondent agreed to participate in the survey, the interviewer confirmed this consent and signed the consent form indicating that the respondent had agreed to participate in the survey.

\section{Appendix}

We assume that $Y_{i}$ is a dichotomous variable taking value 1 , if the $i$-th woman has undergone FGM/C and 0 , otherwise, $i, i=1, \ldots, 8444$. We assumed that variable is 
Bernoulli with an unknown probability $p$ that the woman has undergone the cut. That is, $Y_{i} \sim \operatorname{Bern}\left(p_{i}\right)$ and so we model the risk of FGM/C using a Hierarchical spatial logistic regression model that accounts for excess heterogeneity and spatial similarity between counties. The effects of covariates of different types were modelled as follows:

$$
\operatorname{logit}\left(p_{i}\right)=\beta_{0}+\mathbf{X}_{i}^{\prime} \boldsymbol{\beta}+f_{s}\left(s_{i}\right)+f_{u}\left(s_{i}\right)
$$

where $\boldsymbol{\beta}=\left(\beta_{1}, \ldots, \beta_{p}\right)^{\prime}$ is the $(p \times 1)$ vector of parameter estimates, $\mathbf{X}_{i}$ corresponding linear effects of covariates, $f_{u}\left(s_{i}\right)$ is a spatial unstructured component, which is independent and identically distributed with zero mean and unknown precision, $\tau_{u}$, and $f_{s}\left(s_{i}\right)$ is spatially structured component which is assumed to vary smoothly from region to region. To account for such smoothness $f_{s}\left(s_{i}\right)$ is modelled as an intrinsic Gaussian Markov random field with unknown precision, $\tau_{s}$, [60]. This is the usual conditionally autoregressive prior [35]. The latent Gaussian field for this model is $\xi=\left\{\beta_{0},\left\{\beta_{j}\right\},\left\{f_{s}().\right\},\left\{f_{u}().\right\},\left\{p_{i}\right\}\right\}$ with hyperparameter vector $\theta=\left\{\tau_{\beta}, \tau_{u}, \tau_{s}\right\}$. Vague independent Gamma priors are assigned to each of the elements in $\vartheta$.

A similar model was also applied to the case where the response was the dichotomous variable taking a value 1 if the woman felt that FGM/C Should FGM/C be continued and 0 otherwise.

\section{Competing interests}

The author declares that he has no competing interests.

\section{Acknowledgements}

I would like to thank the School of Public Health, University of the Western Cape for the postdoctoral fellowship granted and the School of Mathematics, Statistics and Computer Science, UKZN for the grant given in support of this work. I would also like to thank Measures DHS for making the data freely available.

Received: 10 July 2013 Accepted: 18 March 2014

Published: 25 March 2014

\section{References}

1. Bjälkander O, Bangura L, Leigh B, Berggren V, Bergström S, Almroth L: Health complications of female genital mutilation in Sierra Leone. International Journal of Women's Health 2012, 4:321-331.

2. World Health Organization: Female genital mutilation, Media Centre; 2000. Fact sheet $N^{\circ} 241$. 2000. Available from: http://collections. infocollections.org/ukedu/en/d/Js0519e/.

3. Rymer J: Female genital mutilation. Curr Obstet Gynecol 2003, 13(3):185-190.

4. Toubia N: Female circumcision as a public health issue. N Engl J Med 1994, 331(11):712-716.

5. Almroth L, Bedri H, el Musharaf S, Satti A, Idris T, Hashim MSK, Suliman Gl, Bergström S: Urogenital complications among girls with genital mutilation: a hospital-based study in Khartoum. Afr J Reprod Health 2005, 9(2):118-124.

6. Behrendt A, Moritz S: Posttraumatic stress disorder and memory problems after female genital mutilation. Am J Psychiatry 2005, 162(5):1000-1002.

7. Dare F, Oboro V, Fadiora S, Orji E, Sule-Odu A, Olabode T: Female genital mutilation: an analysis of 522 cases in South-Western Nigeria. J Obstet Gynecol 2004, 24(3):281-283.
8. Kaplan A, Hechavarría S, Martín M, Bonhoure I: Health consequences of female genital mutilation/cutting in the Gambia, evidence into action. Reprod Health 2011, 8(26):1-6.

9. Morison L, Scherf C, Ekpo G, Paine K, West B, Coleman R, Walraven G: The long-term reproductive health consequences of female genital cutting in rural Gambia: a community-based survey. Trop Med Int Health 2001, 6(8):643-653.

10. Dirie $M$, Lindmark $G$ : The risk of medical complications after female circumcision. East Afr Med J 1992, 69(9):479-482.

11. Abd El-Naser T, Farouk A, El-Nashar AE-R, Mostafa T: Sexual side effects of female genital mutilation/cutting May Be type dependent: a hospitalbased study. J Obstet Gynecol 2011, 1(2):65-74.

12. Alsibiani SA, Rouzi AA: Sexual function in women with female genital mutilation. Fertil Steril 2010, 93(3):722-724.

13. Banks E, Meirik O, Farley T, Akande O, Bathija H, Ali M: Female genital mutilation and obstetric outcome: WHO collaborative prospective study in six African countries. Lancet 2006, 367(9525):1835-1841.

14. Dorkenoo E: Combating female genital mutilation: an agenda for the next decade. World Health Stat Q 1996, 49(2):142.

15. Eke N, Nkanginieme KEO: Female Genital Mutilation: A Global bug that should not cross the millennium bridge. World J Surg 1999, 23(10):1082-1087.

16. Kenya National Bureau of Statistics and ICF Macro: Kenya Demographic and Health Survey 2003. Calverton, Maryland: KNBS and ICF Macro; 2003.

17. Kenya National Bureau of Statistics and ICF Macro: Kenya Demographic and Health Survey 2008-09. Calverton, Maryland: KNBS and ICF Macro; 2010.

18. Benwell GL, McLennan BR: Visualising Spatial Pattern and Correlation: Observations from the Global Atlas on Violence and Health. In SIRC 99 - The 11-th Annual Colloquium of the Spatial Information: 1999. Dunedin, New Zealand: University of Otago; 1999.

19. Kandala NB, Nwakeze N, Kandala SNII: Spatial distribution of female genital mutilation in nigeria. Am J Trop Med Hyg 2009, 81(5):784-792.

20. Kouba $\sqcup$, Muasher J: Female circumcision in Africa: an overview. Afr Stud Rev 1985, 28(1):95-110.

21. Boyle EH, McMorris BJ, Gomez M: Local conformity to international norms. Int Socio/ 2002, 17(1):5-33.

22. Caldwell JC, Orubuloye I, Caldwell P: Male and female circumcision in Africa from a regional to a specific Nigerian examination. Soc Sci Med 1997, 44(8):1181-1193.

23. MRS-EA: Fact Sheet. Female genital mutilation. In MedicalKenya. 2011. http://medicalkenya.co.ke/2011/02/fact-sheet-female-genital-mutilation/.

24. Hayford SR: Conformity and change: community effects on female genital cutting in Kenya. J Health Soc Behav 2005, 46(2):121-140.

25. Jones SD, Ehiri J, Anyanwu E: Female genital mutilation in developing countries: an agenda for public health response. Eur J Obstet Gynecol Reprod Biol 2004, 116(2):144-151.

26. Klouman E, Manongi R, Klepp Kl: Self-reported and observed female genital cutting in rural Tanzania: associated demographic factors, HIV and sexually transmitted infections. Trop Med Int Health 2005, 10(1):105-115

27. Mackie G, Stokes C, Castle S, Heise L, Raikes A, Watts C, Zwi A, Makinwa P, Jensen A, Bankston C: Ending footbinding and infibulation: a convention account. American Sociological Review 1996, 61(6):999-1017.

28. Mitike G, Deressa W: Prevalence and associated factors of female genital mutilation among Somali refugees in eastern Ethiopia: a cross-sectional study. BMC Public Health 2009, 9(1):264.

29. Satti A, Elmusharaf S, Bedri H, Idris T, Hashim MSK, Suliman G, Almroth L: Prevalence and determinants of the practice of genital mutilation of girls in Khartoum, Sudan. Ann Trop Paediatr 2006, 26(4):303-310.

30. Shell-Duncan B, Hernlund Y: Women without choices: the debate over medicalization of female genital cutting and its impact on a northern Kenyan community. In Female "circumcision" in Africa: Culture, Controversy, and Change. Lynne Rienner Publishers; 2000:109-128.

31. Snow R, Slanger T, Okonofua FE, Oronsaye F, Wacker J: Female genital cutting in southern urban and peri-urban Nigeria: self-reported validity, social determinants and secular decline. Trop Med Int Health 2002, 7(1):91-100

32. Yount KM: Like mother, like daughter? Female genital cutting in Minia, Egypt. J Health Soc Behav 2002, 43(3):336-358.

33. Dunteman GH: Principal Component Analysis. Newbury Park: SAGE publication; 1989. 
34. StataCorp L: Stata Survey Data Reference Manual: Release 11. College Station: Stata Press; 2009.

35. Besag J, York J, Mollie A: Bayesian image restoration with two applications in spatial statistics (with discussion). Ann Inst Stat Math 1991, 43:1-59.

36. Best N, Richardson S, Thomson A: A comparison of Bayesian spatial models for disease mapping. Stat Methods Med Res 2005, 14(1):35-59.

37. MacNab YC: Hierarchical Bayesian spatial modelling of small-area rates of non-rare disease. Stat Med 2003, 22(10):1761-1773.

38. Mollie A, Richardson S: Empirical Bayes estimates of cancer mortality rates using spatial models. Stat Med 1991, 10(1):95-112.

39. Martino S, Rue H: R Package: INLA. Norway: Department of Mathematical Sciences, NTNU; 2009. Available at http://www.r-inla.org/.

40. Rue H, Martino S, Chopin N: Approximate Bayesian inference for latent Gaussian models by using integrated nested Laplace approximations. J Royal Stat Soc B 2009, 71(2):319-392.

41. Rue HA, Martino S: Approximate Bayesian inference for hierarchical Gaussian Markov random field models. J Stat Plann Inference 2007, 137(10):3177-3192.

42. Spiegelhalter DJ, Best NG, Carlin BP, van der Linde A: Bayesian measures of model complexity and fit. J Royal Stat Soc B 2002, 64(4):583-639.

43. Kulldorff M: SaTScan-Software for the spatial, temporal, and space-time scan statistics. Boston: Harvard Medical School and Harvard Pilgrim Health Care; 2010.

44. Anselin L, Syabri I, Kho Y GD: An Introduction to Spatial Data Analysis. Geogr Anal 2006, 38(1):5-22.

45. Besag J, York J, Mollié A: Bayesian image restoration, with two applications in spatial statistics. Ann Inst Stat Math 1991, 43(1):1-20.

46. Berg $\mathrm{RC}$, Denison $\mathrm{E}: \mathrm{A}$ tradition in transition: factors perpetuating and hindering the continuance of female genital mutilation/cutting (FGM/C) summarized in a systematic review. Health care for women international 2013, 34(10):837-859.

47. Lockwood M: Structure and behavior in the social demography of Africa. Popul Dev Rev 1995:1-32

48. Valderrama J: Female genital mutilation: why are we so radical? Lancet 2002, 359(9305):529-530

49. Toubia NF, Sharief E: Female genital mutilation: have we made progress? Int J Gynecol Obstet 2003, 82(3):251-261.

50. World Health Organization: Islamic ruling on male and female circumcision. The Right Path to Health, Health Education through Religion. 1996 [Available from: http://applications.emro.who.int/dsaf/dsa54. pdf]

51. Masho SW, Matthews L: Factors determining whether Ethiopian women support continuation of female genital mutilation. Int J Gynecol \& Obstetrics 2009, 107(3):232-235.

52. Achoka J, Odebero S, Maiyo J, Ndiku J: Access to basic education in Kenya: Inherent concerns. Educ Res Rev 2007, 2(10):275-284.

53. Luseno WK, McPeak JG, Barrett CB, Little PD, Gebru G: Assessing the value of climate forecast information for pastoralists: evidence from southern Ethiopia and northern Kenya. World Dev 2003, 31(9):1477-1494.

54. Lokurosia JC: An assessment of the impact of health compaigns against female genital mutilation in west pokot district. Kenya: Kenyatta University; 2011.

55. Government of Kenya: Children's Bill. Kenya Gazette Supplement No. 18 (Bill No. 4); 2001. Available from: http://www1.chr.up.ac.za/undp/domestic/docs/ legislation_03.pdf.

56. Berg RC, Denison E: Effectiveness of interventions designed to prevent female genital mutilation/cutting: A systematic review. Stud Fam Plann 2012, 43(2):135-146.

57. Brown K, Beecham D, Barrett $H$ : he Applicability of Behaviour Change in Intervention Programmes Targeted at Ending Female Genital Mutilation in the EU: Integrating Social Cognitive and Community Level Approaches. In Female Genital Mutilation, Cutting, or Circumcision. New York USA: Hindawi Publishing Corporation; 2013. Available from: http://www. hindawi.com/journals/ogi/2013/324362/
58. Feldman-Jacobs C, Ryniak S, Wilcher R, Shears K, Ellsberg M: Abandoning female genital mutilation/cutting: an in-depth look at promising practices. Washington, D.C: Population Reference Bureau; 2006.

59. Oloo H, Wanjiru M, Newell-Jones K: Female genital mutilation practices in Kenya: the role of alternative rites of passage: a case study of Kisii and Kuria districts. London, United Kingdom: Feed the Minds; 2011.

60. Rue H, Held L: Gaussian Markov Random Fields: Theory and Applications. Boca Raton-London-New York-Singapore: Chapman \& Hall/CRC; 2005.

doi:10.1186/1471-2458-14-276

Cite this article as: Achia: Spatial modelling and mapping of female genital mutilation in Kenya. BMC Public Health 2014 14:276.

\section{Submit your next manuscript to BioMed Central and take full advantage of:}

- Convenient online submission

- Thorough peer review

- No space constraints or color figure charges

- Immediate publication on acceptance

- Inclusion in PubMed, CAS, Scopus and Google Scholar

- Research which is freely available for redistribution

Submit your manuscript at www.biomedcentral.com/submit
C Biomed Central 